\title{
Transgressões e Adolescência: Individualismo, Autonomia e Representações Identitárias
}

Transgressions and Adolescence: Individualism, Autonomy and Identity Representations

Transgresiones y Adolescencia: Individualismo, Autonomía y Representaciones de Identidad

Carolina Esmanhoto Bertol \& Mériti de Souza

Universidade Federal de Santa Catarina
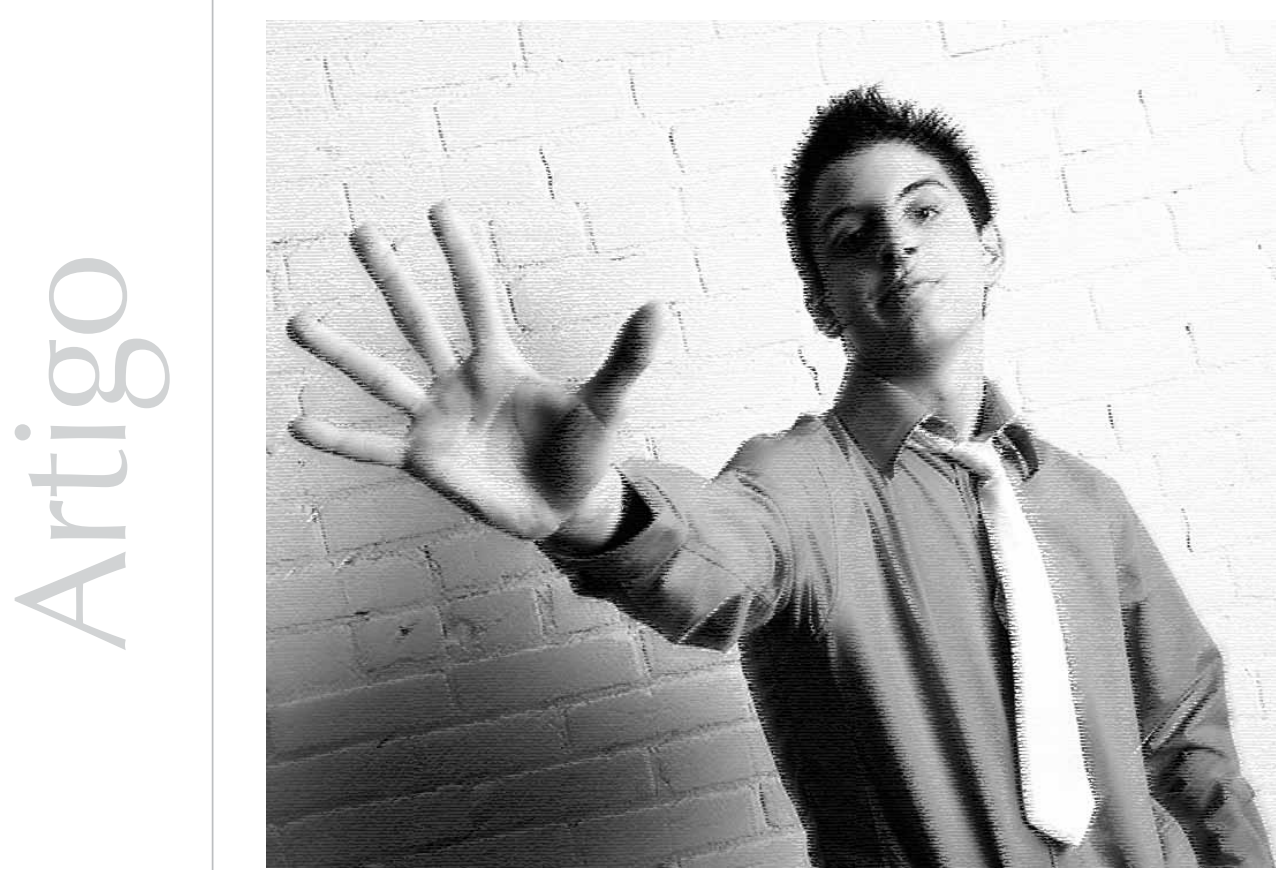
Resumo: No presente artigo, problematizamos a adolescência a partir do pressuposto de que se trata de um conceito construído ao longo da modernidade que passou a ocupar um lugar central nas ciências humanas. Assim, no cenário contemporâneo, esse conceito é compartilhado socialmente, produzindo saberes e delimitando práticas que exercem influência na configuração subjetiva daqueles que compartilham dessa rede social. Referenciais psicanalíticos e psicossociais são utilizados para analisar as representações de adolescência predominantes nas sociedades ocidentais e modernas e as relações entre essas representações e a realização dos ideais de liberdade e de autonomia da sociedade individualista. De forma específica, analisa-se a atribuição da transgressão e da rebeldia como características inerentes à adolescência e as incidências desses atributos na realização desses ideais.

Palavras-chaves: Adolescência. Identificação. Individualismo. Transgressão.

\begin{abstract}
This work attempts to approach adolescence as a concept constructed throughout modern age and that has now gained great importance in human sciences. Thus, in a contemporary background, this concept is shared socially, producing knowledge and delimiting practical processes that exert influence in the subjective configuration of those who share this social net. Psychoanalytical and psychosociological references are used to analyze the predominant representations of adolescence in western and modern societies and the relations between these representations and the accomplishment of the ideals of freedom and autonomy of the individualistic society. Specifically, it analyzes the attribution of transgression and revolt as inherent characteristics of adolescence and the incidences of these attributes in the accomplishment of these ideals. Keywords: Adolescence. Identification. Individualism. Transgression.
\end{abstract}

Resumen: En el presente artículo, problematizamos la adolescencia a partir del presupuesto de que se trata de un concepto construido a lo largo de la modernidad que pasó a ocupar un lugar central en las ciencias humanas. Así, en el escenario contemporáneo, ese concepto es compartido socialmente, produciendo saberes y delimitando prácticas que ejercen influencia en la configuración subjetiva de aquellos que comparten esa red social. Referenciales psicoanalíticos y psicosociales son utilizados para analizar las representaciones de adolescencia predominantes en las sociedades occidentales y modernas y las relaciones entre esas representaciones y la realización de los ideales de libertad y de autonomía de la sociedad individualista. De forma específica, es analizada la atribución de la transgresión y de la rebeldía como características inherentes a la adolescencia y las incidencias de esos atributos en la realización de esos ideales.

Palabras clave: Adolescencia. Identificación. Individualismo. Transgresión.

No cenário das sociedades ocidentais e modernas, a adolescência e suas manifestações são foco de inúmeras análises e preocupações nos diversos setores da população civil e do poder público. Nessa perspectiva, tanto pais e familiares, que se vêm envolvidos com as atitudes e as escolhas de seus filhos, quanto a sociedade em geral, que se preocupa em criar políticas públicas, consideram que seja necessário investir na adolescência e nos adolescentes para produzir cidadãos éticos e úteis para a sociedade. Para muitos pais, educadores e profissionais de diversas áreas, a preocupação em torno da adolescência é legítima e necessária devido à multiplicidade de modelos identificatórios ofertados ao adolescente, que geram uma liberdade de escolha com a qual ele não sabe lidar e que demandam orientação para formar laços sociais. Essa preocupação também é relacionada a mudanças na vida social e pessoal ligadas à demanda pela entrada no mundo adulto.

O contexto desenhado acima nos possibilita afirmar que a adolescência é considerada por grande gama de profissionais, instituições públicas e pais como importante fase da vida. Não obstante, nas inúmeras análises e estudos realizados sobre a adolescência, encontramos múltiplas formas de entendê-la. A mais conhecida caracteriza-a como uma etapa de transição à qual todos os sujeitos do mundo ocidental moderno estariam destinados, um período durante o qual o sujeito, devido ao processo de evolução biológica rumo à maturidade, vivencia a reconstituição de suas referências identitárias, que são localizadas entre a infância e o mundo adulto. Esse sujeito vivencia situações de mudança no corpo 
em decorrência da manifestação de suas funções reprodutivas e, em consequência, experimenta mudanças subjetivas e a reelaboração da sua representação identitária (Muuss, 1969). Outras análises abordam a adolescência não como fase inerente ao humano, mas antes, como criação da era moderna, surgida com o ideário do individualismo, da autonomia, do tempo linear e causal e do progresso. Essa leitura afirma que a adolescência constitui uma relação estabelecida com outros grupos etários e que as características atribuídas a um grupo são construídas culturalmente e mudam de sociedade para sociedade. Assim, o denominado adulto, criança ou velho existe em função da comparação estabelecida entre os membros dessas faixas etárias.

Acreditar ser a adolescência uma fase de construção identitária possibilita a representação do adolescente como rebelde, em constante oposição aos valores da sociedade e às tradições. Por um lado, ele é visto com apreensão, e, por outro, é encarado como alguém que deve ser orientado através da contenção de seus impulsos. Entretanto, perguntamos se essas características atribuídas aos denominados adolescentes são naturais e constitutivas dessa fase da organização subjetiva ou se são produzidas por esse sujeito como resposta ao lugar que a sociedade lhe destina. Perguntamos, ainda, se muitas das características apresentadas pelos adolescentes também não podem ser encontradas nos demais sujeitos não adolescentes constituídos sob a égide do ideário moderno marcado pelo individualismo.

Os impasses relacionados aos estudos do conceito de adolescência e do processo de adolescer entendidos como construção cultural bem como aqueles vinculados aos estudos que problematizam a existência de características inerentes a essa etapa da vida levou-nos a questionar a trajetória que culmina na designação de atributos como a transgressão e a rebeldia aos adolescentes. Para trabalhar essas questões neste ensaio, abordamos a trajetória histórica e social que produz um específico ideário moderno calcado nos preceitos de liberdade, de autonomia e de progresso, concomitante à construção da estrutura subjetiva apoiada em fases de desenvolvimento configuradas por características específicas. Trabalhamos com o pressuposto de que uma das estratégias encontradas pela civilização moderna para preservar os fundamentos de liberdade, autonomia e progresso se encontra no deslocamento desses ideais para a fase da adolescência, com a designação desses atributos ao sujeito que vivencia esse período. Assim, a liberdade e a autonomia presentes na contestação e na rebeldia atribuídas ao adolescente podem ser idealizadas e preservadas nesse momento mítico que deverá ser abandonado em prol da vida adulta. A adolescência prepara para a vida adulta, e espera-se que aquele que vivencia essa fase a abandone para inserir-se como igual na sociedade dos adultos.

\section{Adolescência, adolescências: diferentes leituras}

A origem da palavra adolescência pode ser localizada no verbo adolescere, do latim, que significa crescer em direção à maturidade. Esse crescimento é entendido como desenvolvimento inevitável, e implica transformações sociais, biológicas e psicológicas. Entretanto, é importante mencionar a discordância relacionada à definição da adolescência, já que podemos encontrar tanto aqueles que aceitam a perspectiva desenvolvimentista da qual decorre a concepção da adolescência como etapa do desenvolvimento humano como 
Erikson (1976)

afirmou ser a

adolescência

"um momento

crucial, quando o

desenvolvimento

tem de optar por

uma ou outra

direção, escolher

ou este ou aquele

rumo, mobilizando recursos de crescimento, recuperação e nova

diferenciação" (p. 14). aqueles que não adotam essa perspectiva e trabalham a constituição do subjetivo a partir de referências históricas e sociais. Entre aqueles que trabalham com a perspectiva desenvolvimentista, é grande a divergência acerca das etapas e da sua sequência, o que implica desacordos acerca da idade que marcaria a adolescência, por exemplo.

A leitura denominada desenvolvimentista entende a adolescência como etapa da vida que, como tal, possui características biológicas e psicológicas específicas. Esse rol de características descrito nessa abordagem, entre elas a insegurança, a rebeldia, a impulsividade e a agressividade, passam a ser sinônimos de ser adolescente. Essas características seriam consequência das mudanças biológicas e hormonais que ocorrem nessa fase, e que fixam o adolescente em um período de transição entre a infância e a fase adulta. Nesse processo, o adolescente assumiria uma posição de confrontamento e de oposição aos valores, tradições e leis da sociedade como forma de consolidar sua identidade e sua autonomia frente aos adultos. Erikson (1976) afirmou ser a adolescência "um momento crucial, quando o desenvolvimento tem de optar por uma ou outra direção, escolher ou este ou aquele rumo, mobilizando recursos de crescimento, recuperação e nova diferenciação" (p. 14).

A visão desenvolvimentista aborda a adolescência como fenômeno universal e generalizado, baseando-se na razão como principal mecanismo de aprensão e de vivência no mundo. Através do amadurecimento e do predomínio da razão, o sujeito conseguiria aprender cada vez mais coisas sobre si mesmo e sobre o mundo que o cerca. Esse processo ocorreria até a maturidade, quando o indivíduo já se teria formado, com todas as suas capacidades em funcionamento.
Dentro dessa visão cartesiana racionalistadesenvolvimentista, além da crença em uma identidade adolescente, também se acredita que é nesse período que se constrói a identidade do sujeito. Por isso, tal etapa seria o momento inaugural da personalidade que definiria o sujeito para o resto de sua vida. A identidade do sujeito estaria, então, inevitavelmente atrelada à chegada a um determinado alvo: o nível de racionalidade madura. É a própria primazia da razão que produz a noção/ necessidade dessa identidade do sujeito individual e, conseqüentemente, do seu desenvolvimento. (Coimbra, Bocco, \& Nascimento, 2005, p. 5)

A ideia de evolução até a maturidade, regida pelo desenvolvimento biológico, é alvo de uma das principais críticas feitas à perspectiva desenvolvimentista, pois, a partir dela, o adulto seria entendido como ideal de completude a ser alcançado (Calligaris, 2000; Coimbra et al. 2005; Endo, 2007; Ramírez, 2007). A crítica também é dirigida ao entendimento do adolescente como ser incompleto (no sentido de imperfeição subjetiva), sendo necessária a formação de uma identidade estável, fixa e madura para o seu reconhecimento na rede social. Diversas teorias, porém, como a psicanálise freudiana, entendem que a subjetividade é constituída através de identificações, como operações dinâmicas e imprevisíveis que outorgam ao sujeito a plasticidade associada ao devir. Para Freud, a identidade existe somente como uma fantasia para o sujeito, isso porque o eu, responsável por esse engodo, é formado e está destinado a modificar-se continuamente pelas múltiplas identificações.

A discussão sobre os processos de identificação atravessa praticamente toda a obra freudiana. De forma geral, para Freud (1921/1973), a identificação se refere a um processo psicológico complexo que envolve diferentes momentos. Esse processo possibilita às pessoas elaborar sua constituição subjetiva pautada na ficção identitária de uma unidade 
psíquica que se mantém estável no tempo. As identificações operam a partir de modelos parentais e sociais que funcionam como referências para as pessoas elaborarem a ficção sobre sua constituição subjetiva. É importante ressaltar que, para o autor, o processo de identificação opera inicialmente de forma similar à incorporação de objeto e, dessa forma, precede a relação de objeto. Posteriormente, no seu processo de constituição, o eu consegue representarse como diferenciado do objeto, o que possibilitará à criança realizar investimentos nas figuras parentais e localizar uma figura como objeto de amor e outra como rival na conquista desse objeto de amor. Evidentemente, trata-se aqui da descrição idealizada e generalizada do processo de identificação nos primórdios da vida infantil. Esse processo é singular, e as pessoas se encaminham para várias direções, podendo a criança escolher como modelo identificatório tanto a pessoa amada quanto a pessoa com a qual rivaliza, o que significa que a ficção identitária se forma independentemente da sobreposição ao suporte biológico corporal. Também é necessário ressaltar que a identificação se pauta por movimentos inconscientes, os quais possibilitam que as pessoas se identifiquem com traços do objeto. Para Freud (1921/1973),

10 A identificação é a forma primitiva de enlace afetivo a um objeto; $2^{\underline{O}}$ seguindo uma direção regressiva, se converte em substituição de um enlace libidinoso a um objeto, como por introjeção de objeto no eu, e $3^{\text {o }}$ pode surgir sempre que o sujeito descobre em si uma característica comum com outra pessoa que não é objeto de seus instintos sexuais. Quanto mais importante seja tal comunidade, mais perfeita e completa poderá chegar a ser a identificação parcial e constituir assim o principio de um novo enlace. (p. 2586, tradução nossa)

Nessa perspectiva, é possível entender que a identificação é o processo psicológico que opera em termos da constituição do eu, porém o sujeito vivencia a ilusão identitária de possuir uma identidade integrada e estável.

Ao acompanhar as pesquisas de Ariés (1986), é possível observar que, até o século XVIII, no mundo ocidental e moderno francês, ocorria o uso indistinto do termo enfant tanto para aquele que hoje denominaríamos adolescente quanto para aquele que hoje denominaríamos criança. Em outras palavras, até o século XVIII, os discursos e as práticas sociais que conceituam e produzem a adolescência e a infância se encontravam sobrepostos e não discriminavam essas etapas do desenvolvimento humano e

a longa duração da infância, tal como aparecia na língua comum, provinha da indiferença que se sentia então pelos fenômenos propriamente biológicos: ninguém teria a idéia de limitar a infância pela puberdade. A idéia de infância estava ligada à idéia de dependência. Só se saia da infância ao sair da dependência. (Áries, 1986, p. 46)

Calligaris (2000) também discorre sobre a construção do conceito de adolescência, e afirma que somente de 50 anos para cá esse tema ganhou importância e passou a ser foco de preocupação como grupo social. Para o autor, a adolescência seria inventada devido a um prolongamento da infância, também inventada na modernidade, como demonstrou Ariés (1986). A infância surge com a mudança no sentido da morte, proporcionada pela mudança da sociedade tradicional para o individualismo, e passa a ser o momento idealizado de felicidade, no qual a criança está protegida pelos adultos das disputas sociais. Essa criança surge também como uma forma de os adultos perpetuarem sua existência e realizarem os sonhos que, devido a sua mortalidade, não puderam realizar. Calligaris se pergunta, então, como preparar as crianças para realizar esses desejos 
sem estragar o ideal de felicidade, pois, ao ser encarregada de preparar o futuro e "de se preparar para alcançar um (impossível) sucesso que faltou aos adultos, tanto mais ela se prolonga. Isso inevitavelmente força a invenção da adolescência, que é um derivado contemporâneo da infância moderna" (Calligaris, 2000, p. 67).

A concepção do sujeito constituído no emaranhamento do biológico com a cultura possibilita avaliar a constituição subjetiva na relação com a alteridade, representada por um outro encarnado ou pelos próprios modelos de se constituir determinados e impostos pela rede social. Interessa-nos agora abordar a adolescência como formação cultural da modernidade e as relações estabelecidas com esse ideário, particularmente nos aspectos do individualismo, da liberdade e da autonomia.

\section{Adolescência e modernidade}

\begin{abstract}
A hegemonia alcançada pelo ideário da modernidade nas sociedades ocidentais possibilitou o entendimento do conceito de adolescência como uma fase do desenvolvimento humano, uma continuação da infância. Coutinho (2005) afirma que "só é válido falar em adolescência se nos referimos a um contexto sociocultural individualista, onde a cada indivíduo é delegada a responsabilidade de administrar seu próprio destino, encontrando seu lugar no social da maneira que lhe for preferivel ou possível" (p. 18).
\end{abstract}

O individualismo é entendido por Dumont (1993) como o valor fundador das sociedades ocidentais modernas. O individualismo surgiu quando o homem passou a ser entendido como o valor supremo, mudança que foi proporcionada pelo humanismo e pelas mudanças nas concepções religosas. O homem passou, então, a ter uma relação direta com a razão e com Deus, necessitando da fé somente para exercitar sua religiosidade. Para o autor, as bases do individualismo são os princípios de igualdade e liberdade, segundo os quais o homem é visto como possuidor de propriedades e qualidades inerentes e considerado como ser autônomo e independente de todo e qualquer vínculo social. Segundo Dumont, o termo indivíduo significa tanto um objeto, que é o ser concreto, o modelo individual de ser humano, quanto um valor, que é o ser moral independente e autônomo, representante da ideologia moderna. Na leitura desse autor, com o individualismo, todos os homens são considerados iguais e livres perante o Estado, e as posições sociais que determinavam funções a cada indivíduo são abolidas, supostamente impedindo a intervenção e o controle direto do Estado nas ações e na vida dos indivíduos. O indivíduo rompe todo um sistema de crenças e tradições em busca da liberdade de consciência e passa a primar por sua satisfação pessoal, sendo que, nesse percurso, a existência do outro varia conforme sua necessidade ou não de obtenção da satisfação pessoal. Nessa perspectiva, o homem prevalece sobre a sociedade e o Estado, não se submetendo a ninguém, sendo sua existência regida por regras pessoais.

O termo autonomia foi primeiramente introduzido por Kant para designar "a independência da vontade em relação a qualquer desejo ou objeto de desejo, e a sua capacidade de determinar-se de acordo com uma lei própria que é a da razão" (Abbagnano, 2007, p. 111). O indivíduo autônomo seria aquele que é constituído e guiado pelas leis da sua razão. Nesse termo está implícita a ideia de sujeito e, mais ainda, a de um sujeito que se determina pela sua vontade, pois esta não depende dos seus desejos e do seu contexto social, mas unicamente da razão. A relevância da liberdade e a hegemonia da razão frente às 
tradições e aos dogmas religiosos fazem com que o sujeito individual e suas leis prevaleçam sobre o contexto social. A autonomia passa a ser não somente a forma de apreender $\mathrm{o}$ mundo mas também a forma de controlálo e de dominá-lo através do exercício da razão subjetiva e independente. $\mathrm{O}$ sujeito autônomo é aquele que cria suas próprias leis, ao mesmo tempo em que decide a quais se submeter; em outras palavras, ele é, simultaneamente, legislador e súdito. É aquele que exerce sua liberdade individual e que se constitui através da vontade própria.

Autores como Calligaris (2002), Endo (2007) e Matheus (2008) revelam como foi o surgimento do ideal de um indivíduo autônomo e livre que possibilitou a concepção de adolescência. A partir desse ideal, o homem passa a ser considerado capaz de exercer a autodeterminação e responsável pelas suas escolhas, ações, realizações e autossuperação. Isso significa que o destino do homem não é mais definido pela sociedade, pois ele não teria um papel predeterminado a cumprir, e está pretensamente livre para se inventar, romper tradições e superar-se para se realizar. Essa é a ideia do homem livre e igual a todos, supostamente capaz de construir sua realidade independentemente de seu contexto social, único depositário de todas as conquistas e derrotas que possa alcançar.

Nesse contexto, a adolescência emerge como um momento para o sujeito se preparar para o reconhecimento na rede social e para partilhar essa rede através da constituição de uma identidade definida, que operaria como marca de conclusão do processo de amadurecimento. Durante esse processo, o sujeito enfrentaria os conflitos e desafios necessários para se tornar um indivíduo autônomo, capaz de se autodeterminar independentemente da organização social.
Esse momento de crise, de conflitos e de rebeldia passa, então, a ser encarado como um momento necessário para se atingir a autonomia e para alcançar o status de adulto, caracterizado como o ideal de completude do sujeito moderno.

A adolescência seria, portanto, uma figura identitária produzida por discursos e práticas sociais presentes em determinado momento histórico. Ao longo da modernidade, esse conceito foi ganhando hegemonia, e as características psicológicas e biológicas da adolescência foram sendo determinadas e especificadas para enfim, através da hegemonização de pressupostos científicos, tornar-se um objeto naturalizado (Ariés, 1986; Coimbra et al., 2005; Ramírez, 2007). Entretanto, é necessário questionar a ideia da adolescência como um processo natural do desenvolvimento e criticar o uso do conceito como universal. De fato, os estudos psicológicos e biológicos atrelados aos pressupostos modernos foram os responsáveis pela atribuição de características tidas como inerentes à fase da adolescência, sendo que esse processo permitiu a classificação dos sujeitos em relação às fases estabelecidas (Coimbra et al., 2005).

É importante observar que, mesmo a adolescência tendo sido construída e datada historicamente, ela também produz modos de subjetivar que engendram práticas e discursos que levam as pessoas a se acreditarem e a se representarem como adolescentes, ou seja, a hegemonia alcançada pelos discursos e pelas práticas da e sobre a adolescência passa a constituir a realidade social e psíquica das pessoas que se reconhecem no postulado das etapas desenvolvimentistas. É importante salientar, ainda, que as fases do desenvolvimento passam a constituir focos de interesse das áreas de saber modernas, como a Psicologia, a Medicina, a Pedagogia 
e o Direito, dentre outras. Essas áreas de saber passam a legitimar sua existência devido, entre outros aspectos, às funções e às características que atribuem aos adolescentes e às crianças concomitantemente ao conhecimento que produzem sobre eles. Tendo como principal foco de suas pesquisas o modo como as pessoas são classificadas e o efeito que isso lhes produz, Hacking (2000) afirma:

o nosso conhecimento das pessoas, frequentemente expresso em nossas classificações, tem um enorme efeito sobre nós, e isso pode apenas aumentar no próximo século. Assim, a minha questão está profundamente relacionada com o que uma vez se chamou de natureza humana, exceto por admitir que nossas naturezas são moldadas pelos nossos conceitos. É uma atitude altamente existencialista - nós não nascemos com essências, mas as formamos no mundo social. (p. 10)

Foucault $(1977,2003)$ mostra como a perspectiva assentada na continuidade e na linearidade do desenvolvimento, do progresso e do tempo histórico possibilitará que se naturalize a concepção do humano calcado em essências e etapas. Assim, no processo de construção de saberes sobre as fases do desenvolvimento humano, os estudos científicos produzem normatizações que operam no sentido de reiterar e reproduzir essa conformação subjetiva conforme os atributos estipulados. Em outras palavras, os atributos designados às crianças e aos adolescentes, ao mesmo tempo em que são criticados ou elogiados pelos adultos, sejam eles familiares ou profissionais, também são reproduzidos pelos discursos e práticas desses mesmos adultos na relação com esses sujeitos. Dessa forma, o objeto adolescente nasce sob a égide do discurso e da prática científica moderna, que the atribui uma identidade marcada por um rol de características que Ihe conferem individualidade. Ato contínuo, essa individualidade se assenta na estabilidade identitária e na hierarquia temporal que o discrimina em relação a outras faixas etárias.

A concepção de adolescência que predomina no contexto contemporâneo e que se encontra disseminada na e pela rede social provém da abordagem desenvolvimentista e é reforçada pelas práticas e discursos sociais e científicos, isso porque a caracterização desenvolvimentista da adolescência transforma-a em um fenômeno universal e atemporal, apagando a construção social que sustenta esse conceito e fortalecendo-o como modelo e parâmetro de normatização e de classificação dos sujeitos de nossa cultura. No caso específico da adolescência, esta emerge marcada por características como rebeldia, conflito e transformação, associada a representações do adolescente como rebelde que vive em constante conflito, o que facilitaria uma vertente criativa apta a transformar a realidade.

A adolescência se mostra aos sujeitos como personagem imposto pela rede social a partir de um cronograma que exerce influência não somente na subjetividade daqueles que se reconhecem nesse personagem como também na forma como esse sujeito será posicionado na rede social e no estabelecimento dos laços sociais. A vivência dessa fase, as suas formas de manifestação e até mesmo o seu início e o seu fim são sustentados e impostos aos sujeitos pelos modelos de representação identitária presentes na rede social. Mais uma vez, é a relação com as alteridades e as identificações que aparece entrelaçada à subjetividade, seja para mantê-la presa a um padrão seja para expressá-la em sua diferença, em sua singularidade, com as devidas consequências que a fuga dos padrões pode ocasionar ao sujeito. 


\section{Psicanálise, adolescência e seus processos}

$\mathrm{Na}$ perspectiva psicanalítica, Freud (1905/1973) não falava de adolescência, e sim, de puberdade, que descrevia como um segundo momento de manifestação da sexualidade que ocorre após um período de latência. Nesse momento, o sujeito ressignifica sua sexualidade infantil e seus objetos primordiais, unindo esses últimos e formando o objeto sexual que organizará suas pulsões, unificando-as. O autor compreende ainda que, em decorrência da manifestação dessa sexualidade, agora incrementada pulsionalmente, o sujeito se vê obrigado a passar pelo processo de destituição dos pais como objetos sexuais devido à proibição cultural do incesto. No entanto, Freud não define uma cronologia para a ocorrência dessa manifestação, mas associa-a com as manifestações pulsionais, que, antes de serem determinadas pelo amadurecimento dos aspectos biológicos, são constituídas e transformadas na relação com o outro, pois esse é o fator determinante na formação de objetos sexuais e de configurações subjetivas.

No entanto, muitos psicanalistas entendem que a vivência da puberdade estaria ligada a uma maturação biológica, que provocaria uma nova manifestação da sexualidade que até então estava em estado de latência, e que faria surgir novas sensações. Porém, assim como Matheus (2008), acreditamos que, com essa perspectiva, os conceitos de pulsão e sexualidade seriam entendidos como fatores dependentes somente do biológico. O autor apresenta uma crítica aos pensadores da psicanálise que reforçam a visão desenvolvimentista da adolescência, estabelecendo uma cronologia para sua ocorrência e configurando-a como estado universal e transcendental. Essa universalidade se choca com as concepções de sexualidade e de sujeito singular propostas por Freud, e tendem a manter uma relação de causalidade linear e direta entre as mudanças orgânicas e os processos subjetivos destinados atualmente à adolescência.

Salientamos que, não obstante o fato de ocorrerem mudanças biológicas devido ao processo de maturação do corpo humano, são as relações estabelecidas pelo sujeito com a alteridade que deflagram os caminhos da sexualidade e os processos subjetivos que delas decorrem. Freud (1921/1973), através de estudos sobre as mudanças subjetivas ocorridas quando o sujeito se encontra em um grupo, já afirmava a impossibilidade de separar o social e o individual. Com esse estudo, ele desenvolve o conceito de identificação, demonstrando a importância do outro na constituição subjetiva. Freud (1921/1973) escreve:

o outro está presente na constituição do sujeito, seja como um modelo, um objeto, um auxiliar ou um oponente, de maneira que, desde o começo, a psicologia individual, nesse sentido ampliado porém inteiramente justificado das palavras, é, ao mesmo tempo e desde o princípio, também Psicologia social. (p. 91, tradução nossa)

Nesse sentido, deve-se considerar que a própria puberdade está sujeita à influência da rede social, e que sua vivência dependeria do contexto cultural no qual o sujeito está inserido, e, mais ainda, de sua história singular, que envolve seus desejos e suas fantasias. Recorrendo a essa abordagem, Matheus (2008) afirma que o olhar do outro faz surgir os processos subjetivos descritos para a adolescência, pois esse olhar insere no psiquismo do sujeito um elemento novo que não encontra registro entre os recursos simbólicos já disponíveis: 
Esse olhar e essa imagem não estão presos à concretude da realidade, uma vez que esta é sustentada pelo campo simbólico que a fundamenta e acompanha. Da realidade, busca-se ao menos um grão que sirva de suporte para o real a ser confrontado, disparado pela estranheza do olhar do outro. São as imagens de um corpo transformado, produzidas em meio a esse ou a tantos outros, que instigam o retorno do recalcado, inaugurando o segundo momento da sexualidade. É por esse motivo que o momento adolescente independe imediatamente da puberdade, pois está atrelado aos sentidos que aquele corpo conquista nos laços nos quais se inscreve. (p. 622)

Assim, a entrada na puberdade, bem como a assunção ou não de um modelo de adolescência imposto pela rede social, são decorrentes de uma mudança no laço social estabelecido entre o outro e o sujeito. Com base nos discursos e nas práticas sociais, que estipulam uma forma, e em um cronograma para as vivências subjetivas ao longo do desenvolvimento humano, esse sujeito assume um novo status frente ao olhar do outro e frente ao seu próprio olhar. Com essa mudança frente ao olhar do outro e com a manifestação desse segundo momento da sexualidade, os pais são ressignificados como objetos sexuais. Mas, devido à interdição do incesto como lei fundadora da civilização, o sujeito é impelido a abandonar esse investimento, e, se aceita essa interdição e inscreve em sua subjetividade as leis e as normas culturais necessárias para participar desta civilização, deverá então processar um luto - tanto pela perda dos pais como objetos sexuais quanto pela perda narcísica, sentida no eu ideal - o que culminará em uma sublimação das pulsões e no estabelecimento de identificações com o que antes eram os seus objetos pulsionais. É na tentativa de processar o luto e de formar novos objetos pulsionais que o sujeito se volta para a rede social, constituindo, com esse movimento, um novo ideal (ideal de eu), que será o responsável por regular a formação de novos investimentos pulsionais e de novos laços sociais. Laplanche e Pontalis (2001) ressaltam que o ideal de eu funciona como um modelo ao qual as realizações do eu são comparadas, para averiguar se elas estão ou não em conformidade com esse ideal. Nesse momento, o ideal também carrega as insígnias fálicas do ideal sexual e de escolha do objeto sexual.

Para formar o ideal de eu, o sujeito se baseia nas identificações oriundas das suas relações objetais e nos ideais compartilhados socialmente, os quais foram transmitidos primeiramente pela família. Há uma leitura dos ideais presentes na cultura, que são interpretados pelo sujeito a partir de seus desejos e fantasias. Desse entrelace de elementos, o sujeito faz um caminho referente à posição que irá ocupar nessa rede social e que está relacionada a sua escolha sexual frente às possibilidades que encontra na rede simbólica. É importante lembrar que a denominada escolha sexual implica a assunção de uma representação identitária referente ao masculino e ao feminino, e que esta também impõe ao sujeito um rol de características determinadas como naturais. Em outras palavras, é no momento que o sujeito tem que configurar seu caminho em relação a uma posição que entra em jogo a imposição dos discursos dominantes e naturalizados sobre a subjetividade humana.

Os discursos presentes na rede social que conseguem sua hegemonia são propostos como ideais de subjetividade, e podem ser relacionados ao que Freire Costa (2003) denominou tipo psicológico ordinário. Esse tipo define um perfil com características idealizadas pela rede social e serve como referência para os sujeitos com relação aos seus comportamentos e sentimentos, através dos quais dão significado ao seu campo 
de experiências emocionais. O sujeito que se identifica e que dá significado aos seus sentimentos e ações a partir desse perfil partilha da norma e dos valores dominantes. Assim, se o sujeito reconhece seus sentimentos e maneiras de vivenciar suas experiências nas características postas pelo grupo social no tipo psicológico ordinário, tende a sentir-se satisfeito e aceito pelo grupo. Entretanto, caso não se reconheça nesse perfil, pode experimentar sofrimento, aflição e sentir-se excluído e discriminado pelo grupo ao qual pertence. Entretanto, é necessário salientar que não existe uma relação direta e causal entre corresponder ao tipo psicológico ordinário e sentir-se satisfeito e não corresponder a esse tipo e sentir-se infeliz. De qualquer forma, as análises de Freire Costa possibilitam entender que o processo de constituição subjetiva ocorre via operações identificatórias, e que os ideais sociais presentes nos discursos dominantes e entendidos como naturais são determinantes nessas operações e nos caminhos identitários que o sujeito percorrerá. Isso se dá porque os ideais sociais orientam a configuração do desejo na formação do ideal de eu e das identificações, indicando ao sujeito o necessário para ser reconhecido e valorizado pela sua rede social.

No entanto, os processos de identificação e de luto descritos acima não ocorrem somente em uma etapa da vida do sujeito, definindo a sua constituição e tornando-o estanque, bem como denominada escolha sexual não segue caminhos ditados pela vontade e pela consciência. As identificações ocorrem permanentemente, provocando mudanças subjetivas conforme novos objetos pulsionais vão sendo constituídos e abandonados. O processo de luto é enfrentado por qualquer um que, em determinado momento da vida, se depare com a perda do objeto amado. Esses processos podem ocasionar conflitos, necessitando de escolhas do sujeito, mas são processos sempre singulares, constantes e inconscientes, não podendo ser entendidos como universais e determinantes do destino do sujeito.

A descrição da adolescência como momento de constituição de uma identidade plena, coesa, adulta e que compreende a conclusão da constituição subjetiva esbarra na concepção da singularidade do sujeito e na irredutibilidade e mobilidade das pulsões, que são vistas como fundamentais para a subjetivação no pensamento psicanalítico. Nessa perspectiva, se reforçamos a ideia de manifestações naturais na adolescência, dificultamos a possibilidade de o sujeito se expressar em sua singularidade, e, se ela se manifesta, corremos o risco de não escutá-la, encaixando-a nos padrões de anormalidade e normalidade consolidados pelos discursos desenvolvimentistas e reforçados pelos ideais modernos.

\section{A atribuição da rebeldia à adolescência}

Interessa, neste momento, apontar algumas especificidades do contexto social e histórico -como o individualismo e seu ideal de liberdade - no qual emerge o conceito de adolescência, e que permitiram caracterizá-la como um período de conflito e de oposição às normas sociais. As relações entre a atribuição dessas qualidades e a contextualização desse conceito se mostram relevantes para o entendimento desse tema frente ao discurso social que se apresenta atualmente sobre o adolescente, principalmente frente às manifestações de violência e de transgressão das leis sociais.

Como já apontado anteriormente, o conceito de adolescência emergiu juntamente ao de individualismo, que tem como um de 
seus princípios norteadores a realização do sujeito independentemente da rede social. Se na sociedade tradicional se esperava que o sujeito cumprisse o destino que lhe era assegurado socialmente, com o advento do individualismo, espera-se que o sujeito se situe, crie o seu próprio destino, abstraindo o que a tradição e o seu nascimento lhe reservaram. Com isso, cria-se a ideia de uma pretensa liberdade para o sujeito se situar e se realizar, sem considerar a rede social, com responsabilidade por suas escolhas e por suas conquistas. Assim, todos os homens passam a ser considerados livres e iguais, dependentes apenas da sua vontade e de suas capacidades individuais para realizarem seus objetivos, obterem o sucesso ou experimentarem o fracasso. Essa leitura possibilita que seja anulado e desresponsabilizado todo um contexto social e histórico que se relaciona com a constituição subjetiva e com as ações das pessoas e dos grupos. (Calligaris, 2000; Coimbra et al., 2005; Matheus, 2008; Ramírez, 2007).

Portanto, já encontramos implícitas na concepção do individualismo embasado pela constituição e realização de um indivíduo autônomo - que supera o lugar que lhe está destinado socialmente através da quebra de tradições - a necessidade da transgressão e da rebeldia. Ao pesquisarmos os sentidos dessas palavras, vamos descobrir que a transgressão, além do sentido de quebrar e burlar normas, é definida também como o ato de ir além, de ultrapassar os limites, e que a palavra rebeldia significa oposição, insurgir-se, e também a qualidade daquele que é obstinado. Assim, pode-se dizer que a transgressão e a rebeldia são características necessárias a qualquer sujeito que, formado nos princípios do individualismo, busca a realização do ideal de autonomia. Nessa perspectiva, a transgressão das tradições e de uma ordem estabelecida é considerada não só movimento necessário para a obtenção da autonomia mas também marca do individualismo. Entretanto, essas mesmas ações são condenadas pela civilização, que as enxerga como uma ameaça para a ordem social, entendendo ser necessária a sua repressão através de punições exemplares. Cria-se, então, um paradoxo, pois esperase do sujeito individualista autônomo que transgrida e supere as normas e vá além do que lhe é destinado bem como se espera que ele cumpra as normas e respeite a tradição estabelecida. Esse paradoxo faz com que a rede social procure conter e reprimir os atos transgressivos, obrigando o sujeito a se submeter às normas e às tradições construídas pelas gerações precedentes, concomitantemente ao elogio da capacidade de transgredir, de inovar e de mudar a ordem estabelecida. Uma solução de compromisso que opera nesse cenário é a atribuição majoritária do individualismo e da autonomia à adolescência. Assim, essas aspirações e características são definidas como atributos da adolescência, e as ações e manifestações de contestação, rebeldia e transgressão são consideradas atributos naturais de uma fase da vida.

Vestido com outras roupagens, o paradoxo descrito acima foi apontado por Freud (1930/1973) como um dos principais desafios do sujeito moderno. Para o autor, seria possível que as pessoas alcançassem a satisfação pulsional apenas a partir da sua inserção social, mas, ao mesmo tempo, essa inserção impõe restrições à satisfação de suas pulsões, sendo necessários mecanismos de sublimação, de identificação e de recalque para auxiliá-las nesse processo. Sobre esse paradoxo proposto pela ordem civilizacional, Marin (2003) entende que a subjetivação é um jogo de transgredir e de aceitar limites, no qual o sujeito precisa se inserir e compartilhar uma rede social e, de forma concomitante, 
manter sua autonomia. Em outras palavras, ao mesmo tempo em que o sujeito necessita da rede social para satisfazer suas pulsões, também precisa conservar sua singularidade e autonomia como forma de satisfazer-se narcisicamente.

É nesse sentido que Marin (2003) entende a adolescência - da forma como é representada atualmente na rede social - como o paradigma do sujeito moderno, pois, através da descrição e da determinação dessa etapa da vida, está descrito também o paradigma de todos os sujeitos submetidos à civilização. A autora entende, ainda, que todo processo de subjetivação implica lidar com a violência interna, pois a própria natureza das pulsões é violenta, por ser uma força que irrompe no sujeito e o impele à ação. A adolescência é apenas o momento em que é permitida a manifestação desse processo de subjetivação presente em todos os sujeitos. Esse conflito, que Freud descreve como o responsável pelo mal-estar na civilização, não é vivenciado somente na etapa de vida descrita como adolescência, mas é um conflito inerente à subjetividade moderna e que acompanhará o sujeito durante toda a vida.

Calligaris (2000) afirma que a pretensa rebeldia que caracteriza a adolescência configura de fato a realização de um ideal de autonomia e de liberdade inscritos na modernidade. A rebeldia se manifesta como forma de se opor às tradições e de se realizar de forma autônoma. Entretanto, para o autor, essa rebeldia não é um privilégio somente dos adolescentes, mas representa um dos ideais que passaram a fazer parte da rede social a partir das transformações que se verificaram desde a sociedade tradicional até a sociedade moderna, que têm como princípio o individualismo. O autor ainda pontua que é o ideal de autonomia que constitui o ato de ensinar de forma problemática nos dias atuais, pois o conteúdo transmitido é paradoxal: "a ordem transmitida (quer dizer, a tradição) é de contradizer a tradição" (p. 64). Assim, os sujeitos aprendem que, para se realizar e obter reconhecimento, é preciso se reinventar, quebrar as tradições, criar, o que colide com a demanda hierárquica e com as práticas de normatização postas na e pela escolarização.

Nessa perspectiva, é possível entender a construção da adolescência como esse tempo de transição, transgressão e rebeldia que funcionaria, portanto, como um espelho, um ideal identificatório através do qual os adultos poderiam almejar a felicidade através da hipotética suspensão das normas que regem a vida de todos no momento em que se submetem às leis civilizacionais. Calligaris reforça a ideia da constituição da adolescência como o período no qual seria supostamente possível a satisfação dos desejos, deixando de lado os deveres e as obrigações que constrangem os adultos. Dessa forma, a rebeldia e a transgressão, como atributos próprios do público adolescente, permitem a manutenção do desejo de liberdade dos adultos e, ao mesmo tempo, servem para manter a coesão necessária à civilização moderna:

um mito, inventado no começo do século $X X$, que vingou sobretudo depois da Segunda Guerra Mundial. A adolescência é o prisma pelo qual os adultos olham os adolescentes e pelo qual os próprios adolescentes se contemplam. Ela é uma das formações culturais mais poderosas de nossa época. Objeto de inveja e de medo, ela dá forma aos sonhos de liberdade ou de evasão dos adultos e, ao mesmo tempo, a seus pesadelos de violência e desordem. (Calligaris, 2000, p. 9)

Conforme se explicita, embora a transgressão e a rebeldia sejam características necessárias 
à realização do individualismo, elas são destinadas, pelo discurso social dominante, ao adolescente. Esse processo possibilita que o ideário moderno se sustente e não exponha suas entranhas configuradas por discursos paradoxais. Mas a atribuição dessas características aos adolescentes também ocorre devido ao ideal de completude e de indivíduo autônomo (que tem sua representação na forma adulta), o qual, por sua vez, destina o adolescente a uma incompletude subjetiva e ao processo de construção de uma identidade. Por ser entendido como um sujeito ainda em formação, o adolescente é descrito como um ser em busca de sua autonomia, e, dessa forma, encontrar-se-ia mais propenso a transgredir e a se opor às tradições e às normas culturais, constituindo, assim, potencial ameaça à ordem civilizacional. A forma adulta, por sua vez, seria o momento no qual o sujeito já teria alcançado sua autonomia, etapa na qual adquiriu o domínio de seus afetos, de suas pulsões, e conseguiu controlá-las, submetendo-se às leis da civilização. Já o adolescente se encontraria nos meandros dos conflitos entre as pulsões e a civilização, tentando encontrar uma articulação possível entre as duas.

Neste ponto, revela-se imprescindível apontar a ilusão presente no ideário moderno acerca da completude subjetiva e do domínio das pulsões como ponto final do desenvolvimento humano. Sabemos que a pulsão é definida exatamente como força que surpreende o sujeito e que não se deixa controlar pelo eu, impelindo-o à ação. Essa força dotada de grande mobilidade propicia novas identificações e investe de forma continuada em novos objetos amorosos. Esses movimentos constituem as operações constituintes da subjetividade e levam o sujeito a buscar e a construir constantemente uma suposta identidade, justamente por não dispor de uma a não ser como fantasia elaborada pelo eu. A ilusão acerca do controle de si mesmo e do outro é reforçada pela leitura desenvolvimentista, que entende que o processo evolutivo seja sustentado pela razão, a qual iria adquirir capacidade e prevalecer sobre outras formas de manifestação subjetivas, como os afetos. Assim, o adolescente, por não ter desenvolvido ainda toda a sua capacidade cognitiva, estaria mais sujeito a transgredir as leis sociais em prol da satisfação de suas pulsões, sendo necessário reprimi-lo para melhor submetê-lo a essas leis.

Com a emergência e a consolidação do conceito de adolescência e da descrição do seu rol de características, é possível que a sociedade moderna conviva com o parodoxo que ela mesma fez surgir e que é responsável pelo mal-estar civilizatório. Freud já afirmava que tudo aquilo que é recalcado insiste em retornar sob outras formas em busca de satisfação, exigindo continuamente do sujeito uma força de repressão. Com a constituição da adolescência, aquilo que é recalcado nos sujeitos retorna sob a forma de uma etapa de vida na qual a transgressão é natural e possível. Mas, ao mesmo tempo, por essa manifestação ir de encontro ao desejo dos sujeitos, ela deve ser reprimida, como forma de manter o recalque e a ordem social. É dessa forma que a adolescência se torna um personagem idealizado e, ao mesmo tempo, inoportuno, necessitando ser reprimida para também se submeter às leis sociais. Com a assunção desse personagem e de suas manifestações transgressivas e contestatórias, o sujeito encontra a possibilidade de assumir uma posição reconhecida socialmente e até almejada pelos adultos, na qual supostamente alcança a autonomia. Essas manifestações rebeldes embasadas na autonomia tornam-se, então, a maneira de os sujeitos superarem as práticas sociais 
reforçadoras do discurso desenvolvimentista, que acabam por desqualificar os adolescentes como seres que desejam e que são capazes de partilhar a rede social.

Enquadra-se uma faixa da população por entender que ainda não são cidadãos formados e demandam orientação a fim de educar suas pulsões e seus afetos através da razão. Com isso, acaba-se também por desresponsabilizar os sujeitos nessa fase da vida, por entender que estão em um período de transição no qual a transgressão é natural. Entretanto, ao mesmo tempo em que são desqualificados e desresponsabilizados, exige-se uma punição para seus atos, explicitada na demanda social pelo estabelecimento de leis sociais cada vez mais rigorosas, como é o caso da discussão em torno da redução da maioridade penal.
Com a adolescência, a civilização pode, então, expor seus desejos e suas fantasias de agressão, na medida em que entende que a agressividade e a punição constituem ações necessárias na orientação e no disciplinamento dos sujeitos. Assim, a violência contra os adolescentes será continuamente exercida enquanto continuarmos a impor práticas, significados e modalidades de pensar e de sentir estabelecidas como naturais e normais, excluindo formas alternativas e ocultando o jogo de forças e a persuasão presentes na rede social, aspectos fundamentais para as escolhas do sujeito. E, enquanto continuarmos impondo à adolescência esse ideal de liberdade e de felicidade na tentativa de negar os conflitos que surgem no sujeitos a partir da constituição do individualismo e da ordem civilizacional moderna. 


\section{Carolina Esmanhoto Bertol}

Mestre do Programa de Pós Graduação em Psicologia da Universidade Federal de Santa Catarina, Santa Catarina $\mathrm{SC}$ - Brasil.

\section{Mériti de Souza}

Doutora em Psicologia Clínica pela Pontifícia Universidade Católica de São Paulo, São Paulo - SP - Brasil.

E-mail: meritidesouza@yahoo.com

\section{*Endereço para envio de correspondência:}

Av. Afonso Pena, 4730, bloco Pássaros, apto 2502. bairro Chácara Cachoeira. Campo Grande, Mato Grosso do Sul - MS- Brasil. CEP 79040-010.

E-mail: carolbertol@hotmail.com

Recebido 2/10/2009, Aprovado 30/3/2010.

Abbagnano, N. (2007). Dicionário de filosofia (5a ed.). São Paulo: Martins Fontes.

Ariés, P. (1986). História social da família e da criança. Rio de Janeiro: Guanabara.

Calligaris, C. (2000). A adolescência. São Paulo: Publifolha.

Coimbra, C. C., Bocco, F., \& Nascimento, M. L. (2005). Subvertendo o conceito de adolescência. Arquivos Brasileiros de Psicologia, 57(1), 2-11.

Coutinho, L. G. (2005). A adolescência na contemporaneidade: ideal cultural ou sintoma social. Pulsional Revista de Psicanálise, 17(181), 13-19.

Dumont, L. (1993). O individualismo: uma perspectiva antropológica da sociedade moderna. Rio de Janeiro: Rocco.

Endo, P. C. (2007, março). Criação e destruição. Mente e Cérebro. O olhar adolescente: Espelhos da Sociedade, (4), 62-69.

Erikson, E. (1976). Identidade, juventude e crise. Rio de Janeiro: Zahar.

Foucault, M. (1977). Vigiar e punir: nascimento da prisão. Petrópolis, RJ: Vozes.

Foucault, M. (2003). Microfísica do poder. Rio de Janeiro: Graal.

Freire Costa, J. (2003). Violência e psicanálise (3a ed.). Rio de Janeiro: Graal.

Freud, S. (1973). Tres ensayos para una teoria sexual. In S. Freud, Obras Completas (Vol. 2, pp. 1172-1229). Madrid: Editorial Biblioteca Nueva. (Trabalho original publicado em 1905)

Freud, S. (1973). Los instintos e sus destinos. In S. Freud, Obras Completas (Vol. 2, pp. 2039-2052). Madrid: Editorial Biblioteca Nueva. (Trabalho original publicado em 1915)
Freud, S. (1973). Psicologia de las masas y analisis del "yo". In S. Freud, Obras Completas (Vol. 3, pp. 2563-2610). Madrid: Editorial Biblioteca Nueva. (Trabalho original publicado em 1921)

Freud, S. (1973). El malestar en la cultura. In S. Freud, Obras Completas (Vol. 3, pp. 3017-3067). Madrid: Editorial Biblioteca Nueva. (Trabalho original publicado em 1930)

Hacking, I. (2000). Conversando com lan Hacking: entrevista. Episteme, (10), 9-16. Recuperado em 20 de agosto de 2009 de http://www.ilea.ufrgs.br/episteme/portal/pdf/numero10/ episteme10_entrevista_regner.pdf

Kett, J. F. (1993). Descubrimiento y invención de la adolescencia en la historia. Journal of Adolescent Health, (14), 664-672.

Laplanche, J., \& Pontalis, J. B. (2001). Vocabulário de psicanálise (4a ed.). São Paulo: Martins Fontes.

Marin, I. A. K. (2003). Violência e transgressão: interrogando a adolescência. Revista Latinoamericana Psicopatologia Fundamental, 6(3), 94-109.

Matheus, T. C. (2008). Quando a adolescência não depende da puberdade. Revista Latinoamericana Psicopatologia Fundamental, 11(4), 616-625. Recuperado em 06 de julho de 2009, de http://www.fundamentalpsychopathology.org/ art/dez2008/tiago.pdf

Muuss, R. (1969). Teorias da adolescência. Belo Horizonte: Casa do Professor.

Ramírez, J. F. O. (2007). Alternativas de identificación. Una revisión de tema. Revista Científica Guilhermo de Ockham, 5(2), 23-52. Recuperado em 20 de julho de 2009, de http:// dialnet.unirioja.es/servlet/articulo? codigo $=2884332$ 